\title{
Training Needs Assessment of Health Care Professionals in Reproductive, Maternal and Newborn Health in a Low-Income Setting in Tanzania
}

Columba Mbekenga ( $\nabla$ columba.mbekenga@aku.edu )

Aga Khan University https://orcid.org/0000-0002-3322-4057

Eunice Pallangyo

Aga Khan University

Tumbwene Mwansisya

Aga Khan University

Kahabi Isangula

Aga Khan University

Loveluck Mwasha

Aga Khan University

James Orwa

Aga Khan University

Micheal Mugerwa

Aga Khan Health Services

Michaela Mantel

Aga Khan University

Leonard Subi

Ministry of Health Community Development Gender Elderly and Children

Secilia Mrema

Ministry of Health Community Development Gender Elderly and Children

David Siso

Aga Khan Foundation

Edna Selestine

Aga Khan Health Services

Marleen Temmerman

Aga Khan University

Grace Edwards

Aga Khan University 
Research

Keywords: Training needs assessment, healthcare providers, low resource setting, Tanzania

Posted Date: December 1st, 2020

DOl: https://doi.org/10.21203/rs.3.rs-115748/v1

License: (c) (i) This work is licensed under a Creative Commons Attribution 4.0 International License. Read Full License 


\section{Abstract}

\section{Background}

Healthcare delivery globally and particularly in low-income setting is challenged by multiple, complex and dynamic problems. The reproductive, maternal and newborn health (RMNH) care is among the most affected areas resulting into high maternal and neonatal mortality and morbidity across the Sub Saharan region and Tanzania in particular. However, under-investment in adequate education and training of health care providers (HCPs) is reported worldwide and contributes to the critical shortages, and lack of adequate knowledge and skills among HCPs. The aim of this study was to assess the training needs among HCPs of RMNH care in selected health facilities of Mwanza, Tanzania.

Methods

A cross-sectional descriptive and analytic survey using a self- administered questionnaire was conducted in 36 out of 80 health care facilities included in the Government of Canada and Aga Khan Foundation Canada funded Improving Access to Reproductive, Maternal and Newborn Health in Mwanza, Tanzania (IMPACT) project within the 8 Councils of Mwanza region in Tanzania. The training needs assessment (TNA) tool adapted from the Hennessy-Hicks' Training Needs Assessment Questionnaire (TNAQ) instrument was used for data collection. The HCPs provided ratings on the importance of their task and their current performance of the task. The differences in scores were calculated to identify the greatest training needs.

Results

Out of $153 \mathrm{HCPs}$ who responded to the TNA questionnaire, majority were registered $(n=62)$ and enrolled $(n=43)$ nurses. Ninety percent $(n=137)$ were from government-owned health facilities, mostly from hospitals 68 (45\%). Training needs were high in 16 areas (out of 49 ) including cervical cancer screening and care; accessing research resources; basic and comprehensive emergency obstetric and newborn care; and sexual and gender-based violence. The overall perceived importance of the training needs was significantly associated with perceived performance of tasks related to RMNH services (Pearson Correlation $(r)=.256 ; p<001)$.

Conclusions

The study highlights 16 (out of 49) training gaps as perceived by HCPs working in RMNH in Tanzania. The utilization of findings from the TNA has great potential to facilitate designing of effective trainings for local RMNH services delivery hence improve the overall quality of care.

\section{Background}

Healthcare delivery globally and particularly in low-income setting is challenged by multiple, complex and dynamic health problems(1). There is a need for changes in formal education and continuous 
professional trainings to ensure sufficient quantity and quality of healthcare professionals. However, under-investment in quality education and training of healthcare providers (HCPs) is reported worldwide and contributes to the critical shortages, and lack of adequate knowledge and skills among HCPs (2). The incongruity between education strategies, health system requirements and community demands also affects the quality of maternal and newborn care in healthcare systems (3).

In Sub-Saharan Africa, 36 countries including Tanzania, are considered to have a critical shortage of HCPs to provide minimum coverage of basic services in reproductive, maternal and newborn health $(\mathrm{RMNH})$ and this problem is predicted to exacerbate in the future (4). The Sustainable Development Goals (SDG 3, target 3) emphasizes on the development of HCPs with adequate training, education and skills which are relevant to the needs of the population (5). This investment for better health will also contribute to improved economic growth and achievement of other SDGs (5).

Tanzania has an unacceptably high maternal mortality ratio (556 per 100,000 live births) and neonatal mortality ratio (25 per 1000 live births) (6). The areas bordering Lake Victoria (Mwanza inclusive) and Western zones have the highest rates of mortality (7). In an effort to reduce the problem, the Tanzania government has prioritized the RMNH agenda in its policies and two programmes were launched following this: Sharpened One Plan and Big Results Now (7). These programmes focused on strengthening RMNH services in all regions but with an emphasis on the most affected areas. These government efforts, with support from several stakeholders have reported impressive progress in initiation of basic emergency obstetric and newborn care services (BEmONC) and comprehensive emergency obstetric and newborn care services (CEmONC) in health facilities in Mwanza and other regions (7). However, the evaluation of these efforts particularly in remote areas highlights that suboptimal clinical skills and knowledge of HCPs remain a critical challenge and a potential obstacle for sustaining and consolidating the achievements (7). Furthermore, dissatisfaction with care related to HCPs low competencies, poor communication and lack of respect and dignity to mothers and families are also reported to contribute to negative experiences and uptake of care (8). One of the negative outcomes of undesirable experiences of care could be an explanation for the low rates of childbirth at health facility reported in Tanzania particularly in rural areas (6).

Several interventions to strengthen HCPs' skills predominantly within the scope of midwifery practice have made remarkable contributions in reducing maternal and neonatal mortality and morbidity in countries where the burden was high (9-11). The need for stakeholders' efforts in strengthening capacity and innovative long-term solutions for human resource is suggested (7).

Historically, the capacity building and professional development has been addressed through short courses and in-service training. This approach is useful mainly where staff shortages are catastrophic. Conversely, evidence show that such trainings, when they are traditional and class-based, are less effective in addressing health problems (12-14). Onsite short term training (15) and training of HCPs in relevant professional skills is proven successful and better long-term solutions for uplifting and sustaining HCPs' knowledge and skills (9). The Tanzanian government actively encourages upgrading of 
HCPs in rural areas (16). Thus, the aim of this study was to assess the training needs among HCPs of RMNH care setting in government-owned and designated faith-based health facilities of Mwanza region. This baseline survey was conducted to inform the designing and implementation of the Improving Access to Reproductive, Maternal and Newborn Health in Mwanza, Tanzania (IMPACT) project interventions that aim at strengthening human resource capacity and RMNH service delivery in Mwanza. The IMPACT project is funded by the Government of Canada and the Aga Khan Foundation Canada (AKFC). The project is implemented in Tanzania by a consortium of Aga Khan Development Network (AKDN) agencies, namely the Aga Khan Health Services Tanzania (AKHST), Aga Khan Foundation in Tanzania (AKFT), and the Aga Khan University East Africa (AKU EA), in partnership with the Tanzanian Government through Ministry of Health, Community Development, Gender, Elderly and Children (MoHCDGEC) and President`s Office Regional Administration and Local Government (PO RALG) at national, regional, district levels and local communities. The survey included three components: household coverage survey, health facility survey and training needs assessment. This paper reports the results from the training needs assessment component.

\section{Methods}

This study employed a cross-sectional quantitative study design. Data for this study were collected as part of the baseline TNA for the IMPACT project conducted in 2017. Health care providers working in RMNH of selected health facilities responded to a self-administered questionnaire to identify individual priority training needs.

\section{Study setting}

The study took place in selected government-owned and designated faith-based healthcare facilities in all eight Councils of Mwanza region: Buchosa, Ilemela, Kwimba, Magu, Misungwi, Nyamagana, Sengerema and Ukerewe (17). This region is located in the northern part of Tanzania with about 3 million inhabitants (17).

\section{Study Population}

The participants included all HCPs who were a) working in the labour ward and assisting the deliveries; and 2) working in reproductive and child health clinics (under-five clinic, family planning, immunization units) at the time of the study. The study included HCPs who could fluently communicate and understand either Kiswahili or English language and provided written consent to participate. We excluded HCPs who were found in RMNH and usually not working in these care settings and those who were sick during data collection.

\section{Data collection tool}

The TNA tool was adapted from a validated WHO/Hennessy-Hicks tool (20) with 49 items focusing on capacity and training needs of RMNH health personnel. Prior to actual data collection, the researchers 
visited the field to familiarize with the context and gain insights on the planning of the study and the intervention. Field visit notes and the existing evidence from the study context inspired the modification of the Hennessy-Hicks training needs analysis questionnaire. This questionnaire has been internationally validated and considered successful in identifying and prioritizing training needs at the individual, group or organizational level (20). Inspired by this tool, researchers developed a questionnaire with 49 items to assess individual training needs of HCPs in reproductive healthcare in general for maternal, adolescents and newborns ( 36 items), leadership and management skills ( 9 items), and research skills ( 5 items). The reliability and validity of the developed TNA questionnaire was determined and the reliability of the adapted was found to be 0.954 . The indexes for construct validity indicated that Comparative Fit Index was equal to 1, minimum discrepancy per degree of freedom (CMIN/DF) was equal to 0.000 and the root mean square error of approximation (RMSEA) was equal to 0.185 . This indicates that the TNA questionnaire has acceptable psychometric properties.

\section{Data collection procedure}

Data was collected from HCPs working in 36 sampled government-owned and designated faith-based healthcare facilities ( 7 hospitals, 12 health centres and 17 dispensaries) using the modified and an internationally validated questionnaire. The self-administered questionnaires were distributed to 153 participants by research assistants supervised by one of the researchers from the research team. The eligible RMNH providers were identified by the in-charge of the health facility.

Four research assistants with experience in data collection in RMNH were involved. They were trained for nine days around the best practices on data collection, obtaining informed consent, adherence to ethics as applied to human subjects' research and data security measures.

\section{Pilot study}

A pilot was conducted in one government hospital that was selected based on how similar its characteristics were with the facilities that were to be included in the TNA baseline survey and this facility was excluded in the actual survey. The results from the test were discussed with research assistants, clarifications made, and minor modifications done including adjustment of the flow of the questions.

\section{Sampling and sample size}

Healthcare providers were selected from 36 sampled out of 80 health facilities supported by the IMPACT project. The healthcare facilities involved seven out of eight hospitals in eight districts in the region, 12 out of 19 health centres, and 17 out of 53 dispensaries all under the IMPACT project. The HCP sample size was determined by the IMPACT project's needs. The sampled facilities included $63 \%$ of health centres and $32 \%$ of dispensaries within the IMPACT project that were considered sufficient to provide the required study power. Furthermore, the health centres were selected based on their ranking for high RMNH services utilization, while the dispensaries were randomly selected based on the homogeneous 
characteristics, that is, infrastructure, service provision and human resource capacity. All HPCs present in the sampled facilities were eligible to be included in the study.

\section{Data analysis}

The Statistical Package for Social Science (SPSS, version 20.0) was used for data entry and statistical analysis. Both descriptive and inferential statistics were performed. The HCPs provided ratings on: a) how important is the task to their caring role (Rating $A$ ) and $b$ ) how well the task is currently performed (Rating $B$ ) (20), and the differences in scores were calculated to identify the greatest training needs among the studied tasks (20). The greater the difference between rating $A$ and $B$, the greater the training need and was categorized as a top priority i.e. important task, but not well performed. Where a task scored low on both $A$ and $B$, the task was considered a low priority i.e. unimportant task, but not well performed. Where both ratings were rated high, the task required no training i.e. an important task, well performed. The difference in aggregate scores were analyzed indicating the percentage of participants who scored at least five for A minus the percentage of participants who scored at least 5 for $B$. The Chisquare test and correlation coefficient was used to determine the relationship between sociodemographic and task performance and perceived importance between HCPs.

\section{Results}

The TNA questionnaire was completed by 153 eligible HCPs. The age of the participants ranged between 21- 62 years with mean age of $38.70 \pm 10.89$ years. The majority of HCPs in the RMNH units who participated in this study were Registered Nurses $(n=62)$ and Enrolled Nurses $(n=43)$ (Table 1).

\section{Table 1: Participants of the training needs assessment $(\mathrm{N}=152)$}

\begin{tabular}{|lll|}
\hline Cadre & Participants & Percentage \\
\hline Assistant Medical Officers (AMO) & 3 & 2.6 \\
\hline Clinical Officers (CO) & 8 & 5.3 \\
\hline Registered Nurses (RN) & 62 & 41.1 \\
\hline Enrolled Nurses (EN) & 43 & 28.5 \\
\hline Medical Attendants (MA) & 26 & 17.2 \\
\hline Maternal and Child Health Aiders (MCHA) & 10 & 6.2 \\
Total & 152 & \\
\hline
\end{tabular}

*ne participants had missing information on the cadre and was excluded.

AMO-Assistant Medical officers with 3 years of training CO - Clinical officers with 3 years of training in medicine. 
RN - Registered Nurse/Midwife with 3 years of training in nursing and midwifery

EN - Enrolled Nurse Midwife with 2 years of training in nursing and midwifery

MCHA - Maternal and Child Health Aider with 1 year of training in Midwifery

Most of the participants were from the government-owned health facilities 137 (90\%) mostly from the hospital 68 (45\%). Few participants were from faith-based designated district hospitals 16 (10\%). All the participants worked in RMNH units with more than five years of working experience. The total number of health facilities and participants in this study is summarized below (Table 2).

Table 2: Number of health facilities and healthcare providers in the study

\begin{tabular}{|llll|}
\hline Facility & Sampled facilities & Surveyed facilities & Questionnaire Distributed (M/F) \\
\hline Dispensaries & 53 & 17 & $29(8 / 21)$ \\
\hline Health centres & 19 & 12 & $53(8 / 45)$ \\
\hline Hospitals & 8 & 7 & $71(9 / 62)$ \\
\hline Total & $\mathbf{8 0}$ & 36 & $153(25 / 128)$ \\
\hline
\end{tabular}

*Two providers had significant missing information on the type of health facility they work and were excluded in this analysis

\section{Priority training needs}

The difference between the care items with the highest score in rating $A$ and the lowest score in rating $B$ (important task, not well performed) were obtained. The care items with a score of greater than 40 were marked as a high priority area for training. The training needs were the highest in 16 (out of 49) care items including cervical cancer screening and care; research; basic and comprehensive emergency obstetric and newborn care (BEmONC \& CEmONC); and sexual and gender-based violence (Table 3).

\section{Table 3: High Priority training needs}




\begin{tabular}{|c|c|c|c|c|c|c|}
\hline & Care item & $\begin{array}{r}\text { Impo } \\
\text { Rati }\end{array}$ & & $\begin{array}{r}\text { Not-well } \\
R a t\end{array}$ & formed & Difference \\
\hline 1 & Providing care and education for cervical cancer screening and treatment & $136 / 150$ & 90.7 & $58 / 150$ & 38.7 & 52 \\
\hline 2 & Accessing research resources (e.g. time, money, Information, equipment) & $130 / 148$ & 87.8 & $56 / 148$ & 37.8 & 50 \\
\hline 3 & $\begin{array}{l}\text { Competently providing comprehensive emergency obstetric and newborn } \\
\text { care (CEmONC) }\end{array}$ & $127 / 147$ & 86.4 & $56 / 147$ & 38.1 & 48.3 \\
\hline 5 & $\begin{array}{l}\text { Identifying cases of sexual and gender based violence and knowing how to } \\
\text { make appropriate referrals }\end{array}$ & $136 / 151$ & 90.1 & $65 / 151$ & 43.0 & 47.1 \\
\hline 6 & Feeling confident in providing anaesthetic care & $89 / 134$ & 66.4 & $26 / 134$ & 19.4 & 47 \\
\hline 7 & Identifying research needs and designing locally relevant research & $136 / 149$ & 91.3 & $67 / 149$ & 45.0 & 46.3 \\
\hline 10 & $\begin{array}{l}\text { Providing information, education, counselling or family planning services } \\
\text { to adolescents }\end{array}$ & $136 / 153$ & 88.9 & $70 / 153$ & 45.8 & 43.1 \\
\hline 11 & $\begin{array}{l}\text { Providing counselling, care and support for women who are subject to } \\
\text { gender based violence }\end{array}$ & $134 / 151$ & 88.7 & $69 / 151$ & 45.7 & 43 \\
\hline 12 & Evaluating patients' psychological and social needs & $132 / 149$ & 88.6 & $69 / 149$ & 46.3 & 42.3 \\
\hline 13 & $\begin{array}{l}\text { Delivering gender sensitive reproductive, maternal, child and adolescent } \\
\text { health services (such as providing privacy for consultations, gender } \\
\text { sensitive counselling approaches, involvement of men) }\end{array}$ & $145 / 152$ & 95.4 & $81 / 152$ & 53.3 & 42.1 \\
\hline 14 & Planning and organizing an individual patient's care & $136 / 150$ & 90.7 & $74 / 150$ & 49.3 & 41.4 \\
\hline
\end{tabular}

Relationship between demographic characteristics and HCP performance on the stipulated tasks $(\mathrm{N}=153)$

Fisher's exact test was performed to establish if there is any relationship between demographic characteristics i.e. gender, duration of employment and age and perceived performance on the stipulated tasks by health care workers of the RMNH services, where the relationship was not statistically significant (Table 4).

Table 4: Relationship between demographic characteristics and HCP performance on the stipulated tasks 


\begin{tabular}{|c|c|c|c|c|c|c|}
\hline & & Good & Poor & Fisher exact test & df & P-value \\
\hline & Male & 10 & 8 & & & \\
\hline \multirow[t]{2}{*}{ Gender } & & & & 1.057 & 2 & .589 \\
\hline & Female & 66 & 34 & & & \\
\hline \multirow{5}{*}{$\begin{array}{l}\text { Duration of employment } \\
\text { (Years) }\end{array}$} & $0-10$ & 22 & 41 & $4.440 \mathrm{a}$ & 8 & .859 \\
\hline & $11-20$ & 4 & 11 & & & \\
\hline & $21-30$ & 5 & 12 & & & \\
\hline & $31-40$ & 2 & 11 & & & \\
\hline & $41-50$ & 0 & 1 & & & \\
\hline \multirow[t]{4}{*}{ Duration in RMNHC } & $0-10$ & 29 & 62 & 2.565 & 6 & .879 \\
\hline & $11-20$ & 3 & 4 & & & \\
\hline & $21-30$ & 2 & 6 & & & \\
\hline & $31-40$ & 1 & 4 & & & \\
\hline \multirow[t]{5}{*}{ Age-group } & $21-30$ & 16 & 19 & 7.878 & 8 & .441 \\
\hline & $31-40$ & 6 & 19 & & & \\
\hline & $41-50$ & 8 & 17 & & & \\
\hline & $51-60$ & 5 & 18 & & & \\
\hline & $\begin{array}{l}60 \text { and } \\
\text { above }\end{array}$ & 0 & 1 & & & \\
\hline
\end{tabular}

The correlation between demographic characteristics (gender, duration of employment, age) with perceived task importance was generally found to be not statistically significant. However, perceived importance of task was positively correlated with overall performance of task related to RMNH services $($ Pearson Correlation $(r)=.256 ; \mathrm{P}<001)($ Figure 1$)$

Table 5: The gap between the perceived importance and the competence in care provision (49 items) 


\begin{tabular}{|c|c|c|c|c|c|c|}
\hline \multirow{2}{*}{\multicolumn{2}{|c|}{ Care item }} & \multirow{2}{*}{\multicolumn{2}{|c|}{$\begin{array}{l}\% \text { Important } \\
\text { care } \\
\text { (response >=5) } \\
\text { A }\end{array}$}} & \multirow{2}{*}{\multicolumn{2}{|c|}{$\begin{array}{l}\% \text { Well } \\
\text { performed care } \\
\text { (response >=5) } \\
\text { B }\end{array}$}} & \multirow{3}{*}{$\begin{array}{l}\begin{array}{l}\% \\
\text { difference }\end{array} \\
\%\end{array}$} \\
\hline & & & & & & \\
\hline & & $\mathrm{n}$ & $\%$ & $\mathrm{n}$ & $\%$ & \\
\hline 1 & $\begin{array}{l}\text { Understanding gender equality issues } \\
\text { relating to reproductive, maternal, child } \\
\text { and adolescent health }\end{array}$ & $149 / 153$ & 97.4 & $85 / 153$ & 55.6 & 41.8 \\
\hline 2 & $\begin{array}{l}\text { Delivering gender sensitive reproductive, } \\
\text { maternal, child and adolescent health } \\
\text { services }\end{array}$ & $145 / 152$ & 95.4 & $81 / 152$ & 53.3 & 42.1 \\
\hline 3 & $\begin{array}{l}\text { Providing patient friendly reproductive, } \\
\text { maternal, child and adolescent health } \\
\text { services }\end{array}$ & $144 / 152$ & 94.7 & $94 / 152$ & 61.8 & 32.9 \\
\hline 4 & $\begin{array}{l}\text { Understanding and using maternal, new- } \\
\text { born and child health score cards }\end{array}$ & $135 / 152$ & 88.8 & $91 / 152$ & 59.9 & 28.9 \\
\hline 5 & $\begin{array}{l}\text { Providing focused antenatal care } \\
\text { according to WHO guidelines }\end{array}$ & $148 / 153$ & 96.7 & $109 / 153$ & 71.2 & 25.5 \\
\hline 6 & $\begin{array}{l}\text { Offering malaria diagnosis with rapid } \\
\text { diagnostic testing }\end{array}$ & $147 / 153$ & 96.1 & $108 / 153$ & 70.6 & 25.5 \\
\hline 7 & $\begin{array}{l}\text { Providing malaria treatment in } \\
\text { pregnancy }\end{array}$ & $145 / 151$ & 96.0 & $119 / 151$ & 78.8 & 17.2 \\
\hline 8 & $\begin{array}{l}\text { Providing education on voluntary } \\
\text { counselling and testing for HIV/AIDS }\end{array}$ & $149 / 153$ & 97.4 & $107 / 153$ & 69.9 & 27.5 \\
\hline 9 & $\begin{array}{l}\text { Providing education, counselling and } \\
\text { support for HIV/AIDS prevention, care, } \\
\text { and management for adolescents }\end{array}$ & 139/152 & 91.4 & $87 / 152$ & 57.2 & 34.2 \\
\hline 10 & $\begin{array}{l}\text { Competently managing uncomplicated } \\
\text { deliveries }\end{array}$ & $137 / 151$ & 90.7 & $108 / 151$ & 71.5 & 19.2 \\
\hline 11 & $\begin{array}{l}\text { Competently utilising the partograph for } \\
\text { every women in labour }\end{array}$ & $148 / 152$ & 97.4 & $98 / 152$ & 64.5 & 32.9 \\
\hline 12 & $\begin{array}{l}\text { Competently providing basic emergency } \\
\text { obstetric and new-born care (BEmONC) }\end{array}$ & $144 / 152$ & 94.7 & $78 / 152$ & 51.3 & 43.4 \\
\hline 13 & $\begin{array}{l}\text { Competently providing comprehensive } \\
\text { emergency obstetric and new-born care } \\
\text { (CEmONC) }\end{array}$ & 127/147 & 86.4 & $56 / 147$ & 38.1 & 48.3 \\
\hline 14 & $\begin{array}{l}\text { Competently managing severe intra- and } \\
\text { postpartum haemorrhage }\end{array}$ & $143 / 152$ & 94.1 & $98 / 152$ & 64.5 & 29.6 \\
\hline 15 & $\begin{array}{l}\text { Competently managing women } \\
\text { suffering from severe pre-eclampsia and } \\
\text { eclampsia }\end{array}$ & $144 / 151$ & 95.4 & $92 / 151$ & 60.9 & 34.5 \\
\hline
\end{tabular}




\section{New-born care skills}

16 Effectively resuscitating new-borns using the new-born bag and mask (HBB-

$142 / 150$

$94.7 \quad 101 / 150$

$67.3 \quad 27.4$

Helping Babies Breathe)

17 Identifying danger signs and

$145 / 153$

94.8

$108 / 153$

70.6

24.2

complications in child birth and

effectively managing maternal and new-

born referral for further investigations or

treatment

18 Providing education and counselling on

prevention of mother to child

transmission of HIV (PMTCT)

$\begin{array}{lllll}147 / 151 & 97.4 & 112 / 151 & 74.1 & 23.3\end{array}$

tansmission of HIV (PMTCT)

19 Effectively managing PMTCT treatment $\begin{array}{lllll}146 / 153 & 95.4 & 99 / 153 & 64.7 & 30.7\end{array}$ of HIV positive pregnant women, mothers and infants

20 Providing education and support to mothers in initiation of breast feeding within one hour of delivery and exclusive breast feeding for 6 months

21 Implementing the maternal infant and young child nutrition programme

$\begin{array}{lllll}149 / 153 & 97.4 & 123 / 153 & 80.4 & 17.0\end{array}$

Offering the Tanzania expanded
programme for immunization (EPI)

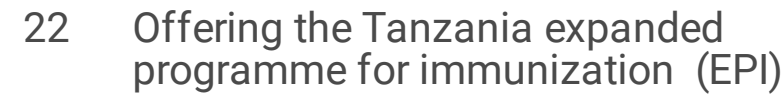

$\begin{array}{lllll}143 / 152 & 94.0 & 93 / 152 & 61.2 & 32.8\end{array}$

23 Understanding vaccine management and logistics (cold chain maintenance)

$\begin{array}{lllll}138 / 148 & 93.2 & 74 / 148 & 50.0 & 43.2\end{array}$

24 Being proficient on injection safety and $\begin{array}{lllll}151 / 153 & 98.7 & 131 / 153 & 85.6 & 13.1\end{array}$

infectious waste management

$138 / 149 \quad 92.6 \quad 84 / 149 \quad 56.4 \quad 36.2$
Family planning

25 Providing family planning services to $\quad \begin{array}{lllll}141 / 153 & 92.2 & 93 / 153 & 60.8 & 31.4\end{array}$ women and men in a union

26 Providing family planning services to unmarried/single women and men

$\begin{array}{lllll}140 / 153 & 91.5 & 83 / 153 & 54.2 & 37.3\end{array}$

Providing infomation, education.

27 Providing information, education, counselling or family planning services to adolescents

$136 / 153 \quad 88.9 \quad 70 / 153 \quad 45.8 \quad 43.1$

\section{Screening and Surgical reproductive care}

28 Providing care and education for cervical cancer screening and treatment

29 Feeling confident in providing surgical care (including caesarean section)

\begin{tabular}{|lllll}
\hline $136 / 150$ & 90.7 & $58 / 150$ & 38.7 & 52 \\
\hline $88 / 129$ & 68.2 & $27 / 129$ & 20.9 & 47.3
\end{tabular}




\begin{tabular}{|c|c|c|c|c|c|c|}
\hline 30 & $\begin{array}{l}\text { Feeling confident in providing } \\
\text { anaesthetic care }\end{array}$ & $89 / 134$ & 66.4 & $26 / 134$ & 19.4 & 47 \\
\hline 31 & $\begin{array}{l}\text { Identifying cases of sexual and gender } \\
\text { based violence and knowing how to } \\
\text { make appropriate referrals }\end{array}$ & $136 / 151$ & 90.1 & $65 / 151$ & 43.0 & 47.1 \\
\hline 32 & $\begin{array}{l}\text { Providing counselling, care and support } \\
\text { for women who are subject to gender } \\
\text { based violence }\end{array}$ & 134/151 & 88.7 & $69 / 151$ & 45.7 & 43 \\
\hline 33 & $\begin{array}{l}\text { Planning and organizing an individual } \\
\text { patient's care }\end{array}$ & $136 / 150$ & 90.7 & $74 / 150$ & 49.3 & 41.4 \\
\hline 34 & $\begin{array}{l}\text { Evaluating patients' psychological and } \\
\text { social needs }\end{array}$ & $132 / 149$ & 88.6 & $69 / 149$ & 46.3 & 42.3 \\
\hline 35 & $\begin{array}{l}\text { Implementing effective infection control } \\
\text { strategies }\end{array}$ & $146 / 153$ & 95.4 & $97 / 153$ & 63.4 & 32 \\
\hline 36 & $\begin{array}{l}\text { Implementing effective disease } \\
\text { surveillance and reporting }\end{array}$ & $140 / 150$ & 93.3 & $77 / 150$ & 51.3 & 42 \\
\hline
\end{tabular}

\section{Leadership and Management skills}

\begin{tabular}{lllllll}
37 & Organising your own time effectively & $143 / 153$ & 93.5 & $112 / 153$ & 73.2 & 20.3 \\
\hline 38 & $\begin{array}{l}\text { Personally coping with change in the } \\
\text { health service delivery }\end{array}$ & $151 / 153$ & 98.7 & $115 / 153$ & 75.2 & 23.5 \\
\hline & & & & &
\end{tabular}

39 Working as a member of a team

$150 / 153 \quad 98.0 \quad 128 / 153 \quad 83.7 \quad 14.3$

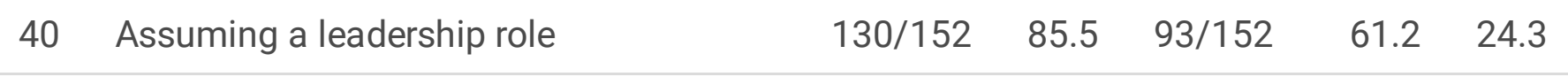

41 Developing leadership skills $\quad \begin{array}{lllll}129 / 153 & 84.3 & 83 / 153 & 54.2 & 30.1\end{array}$

42 Mentoring and guiding other staff $\quad \begin{array}{llllll}147 / 153 & 96.1 & 107 / 153 & 69.9 & 26.2\end{array}$

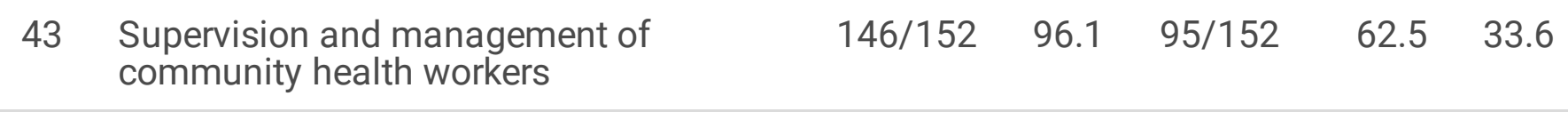

44 Training of community health workers $\quad \begin{array}{llllll}141 / 149 & 94.6 & 88 / 149 & 59.1 & 35.5\end{array}$

\section{Research Skills}

45 Undertaking effective data reporting and $\begin{array}{lllll}147 / 152 & 96.7 & 111 / 152 & 73.0 & 23.7\end{array}$ monitoring of service delivery

46 Statistically analysing your own data $147 / 152 \quad 96.7 \quad 94 / 152 \quad 61.8 \quad 34.9$ and using health facility data to understand local health challenges and inform service delivery

47 Identifying research needs and designing locally relevant research

$\begin{array}{lllll}136 / 149 & 91.3 & 67 / 149 & 45.0 & 46.3\end{array}$

48 Accessing research resources (e.g. time, money, Information, equipment) 


\section{Discussion}

The training need assessment was designed to collect information on training gaps in various clinical RMNH care and identify training needs among health personnel working in sampled health care facilities under the IMPACT project in Mwanza region. The findings of the TNA were critical in guiding the design of the interventions for capacity building among HCPs in the region. The findings highlight the training gaps as perceived by HCPs working in RMNH that indicate training priorities for the study setting in Tanzania.

The findings of this study show that the training needs were the highest in 16 (out of 49) care items. Amongst the identified gaps were: cervical cancer screening and care; basic and comprehensive emergency obstetric and newborn care (BEmONC \& CEmONC); sexual and gender-based violence; providing information, education, counselling on family planning to adolescents; and implementing the maternal, infant and young child nutrition programmes. These findings are supported by research in India, Pakistan and Nigeria where gaps were identified in maternal and newborn care, skills in emergence and basic obstetric care among health providers (21-23). However, for the Pakistan study, the gaps were categorized by cadres where medical doctors poorly performed in $\mathrm{MNCH}$ in comparison with other cadres. Our study did not perform such a comparison, because this was a perception study, we did not observe HCPs' performance. The highlighted training gaps correspond with areas in RMNH with poor indicators in Mwanza and the country in general (24), it is therefore not surprising that HCPs perceived these areas as gaps. For example, there is high maternal mortality rate, neonatal mortality rate and perinatal mortality rate (556 per 100, 000 live births, 25 per 1000 live births and 39 per 1000 live births respectively), only $32 \%$ use of modern contraceptives methods among women of reproductive age, and $42 \%$ of ever married women have experienced spousal violence, whether physical or sexual in Tanzania (19). To enhance providers' competencies, refresher continuing medical educational programmes relevant to specific health care cadres are required.

Previous studies have highlighted barriers preventing HCPs from attending continued education that include negative attitudes (25), time constraints and limited finance to support training (25-27), child care and home responsibilities(26), lack of opportunity and previous negative experience(27). It is critical to have mechanisms in place that ensure health care professionals are continuously supported to attend relevant on-job trainings that will translate in improved RMNH outcomes. Furthermore, the findings of our study call for a collaborative work between professional training institutions and the government to design innovative continuing educational programmes that not only would respond to the needs of HCPs but also include blended short courses that allow flexibility and enhance their clinical practice for improved quality of care. Additionally, health care managers need to understand factors hindering and motivating HCPs from attending continuing educational programmes and set up strategies to promote 
and warrant participation. Addressing the training needs of HCPs may contribute towards achieving reduced maternal and neonatal deaths and morbidities especially in low resource settings.

Surprisingly, accessing research resources (i.e. time, money, information, equipment) and identifying research needs and designing locally relevant research were among the topics that received the highest ratings. This findings contradicts a common stereotype on lack of interest for research among clinicians reported in United Kingdom and Bahrain $(28,29)$. However, the findings from other previous studies indicate a low self -assessed research capacity among nurses $(30,31)$ and a need for training in research methods among nurses and other HCPs $(30,32,33)$. In alignment with our study findings, lack of research resources like time and funding were found to be the most commonly perceived barriers to undertaking research among practitioners in the UK, USA and Bahrain $(28,29,34)$, increased paper work and disruption to work flows (34) and lack of statistical support (29). Among the motivating factors for participating in research included providing benefits to patients, hoping to create knowledge relevant for patient care, finding solutions to difficult health problems and as an opportunity for professional development among clinical staff (34) and research supportive environment such as a research mentor (35). Health care providers in clinical practice are in a unique position to identify health problems and propose relevant evidence based solutions through clinical research. These findings call for innovative strategies for inculcating a research culture and required skills among practicing HCPs including joint research between clinical and academic institutions to design context specific relevant clinical action research with direct impact on patient care.

Overall, the perceived importance on the specific tasks was positively correlated with the overall perceived performance of tasks related to RMNH services. Similarly, findings of a study in South Africa indicated that, the more comprehensively professional nurses were trained, the more competent they felt, and they expressed more negativity towards their work if they perceived they were inadequately trained (36). The fact that the HCPs' perceived importance of the tasks correlated with their perceived performance underscores the need for ensuring strategies are in place to address the identified training gaps. This implies, HCPs may lack confidence in their performance in the areas that were perceived important but with less ability to perform the tasks that might hinder their overall performance. Conversely, in a study among Tanzanian enrolled nurse midwives, more than $90 \%$ of the participants demonstrated both high performance and perceived competence in provision of primary health care services related to family planning, maternal and child care (37). One explanation could be that our study involved HCPs at various levels of care including referral facilities that require advanced skills for provision of RMNH including emergence care as opposed to the above study that only explored the elements of primary health care. Nonetheless, there is a need to tailor the trainings to the needs of the providers, this study was undertaken to determine and contextualize the specific training needs of HCPs in Mwanza.

As expected, majority of HCPs in the studied setting were registered and enrolled nurses constituting 67 percent of all study participants. These findings reflect the overall number of nurses and midwife in Tanzania who constitute more than 60 percent of the total health care workforce in Tanzania(38). 
Nevertheless, the results may be confounded by higher numbers of registered and enrolled nurse midwives that may not be representative of the training needs among other HCPs.

\section{Limitations}

This study was conducted in only one region and therefore might limit the generalization of the findings in broader contexts. However, the sample was obtained randomly thus enabling generalization to the study area. The study used a WHO tool that has not been previously validated within the country. However, in this study, the reliability of the adapted TNA questionnaire was tested and found to be 0.954 . Relatedly, indexes for construct validity was found to at acceptable level with CFI equal to 1, (CMIN/DF) equal to 0.000 and RMSEA of 0.185 , suggesting the tool to having acceptable reliability and validity.

\section{Conclusion}

The results of the current study highlight the training gaps as perceived by HCPs working in RMNH in Tanzania, where 16 (out 49) care items were identified as priority for training. Furthermore, this study demonstrates that the perceived importance of the training needs to be significantly associated with performance of tasks related to RMNH services.

\section{Implication for practice}

The utilization of findings from TNA assessment has great potential to improve local service delivery hence improve the overall quality of care in a particular setting. The findings of this study might be helpful in identification of the training gaps that has potentials to guide the design of continuing professional educational programs among HCPs in Tanzania. The findings could also be used by higher learning educational institutions to strengthen pre and post qualification postgraduate curricula for various professional programmes. Furthermore, since the tool has been validated for use in some low resource countries (Hennessy, D., Hicks, C., Hilan, A., \& Kawonal, Y. (2006); Gaspard, J., \& Yang, C. M. (2016) it may be generalizable to East African countries.

\section{Abbreviations}

BEmONC: Basic emergence obstetric and newborn care; CEmONC: Comprehensive emergence obstetric and newborn care; COSTECH: Tanzania Commission for Science and Technology; HCPs: Health care providers; IMPACT: Improving access to reproductive, maternal, adolescent and newborn health in Tanzania; NIMR: National institute for medical research; MNCH: maternal, newborn and child health; RMNH: Reproductive, maternal and newborn health; SGDs: Sustainable development goals; TNA: Training needs assessment; UK: United Kingdom; USA: United states of America; WHO: World Health organization;

\section{Declarations}


This study was approved by the National Institute for Medical Research Reference: NIMR/HQ/R.8a/vol. IX/2517 on $9^{\text {th }}$ June, 2017. Research permits for all researchers and study clearance were obtained from The Tanzania Commission for Science and Technology (COSTECH). The permission to conduct this survey was sought from the regional, district and health facilities authorities. Detailed information regarding the study was provided to all the participants before embarking on the study. Data was collected only after the informed consent was obtained and consent forms signed. Questionnaires were distributed and left with participants for them to fill at their convenient time and place.

\section{Consent for publication}

Not applicable

\section{Availability of data and materials}

Data to support the findings of this study are available and may only be accessed by those interested who will be required to obtain special permission from the Aga Khan University, Monitoring and Evaluation Research Unit (AKU-MERL).

\section{Competing interests}

Authors declare no competing interest.

\section{Funding}

This study received financial support from the Government of Canada and Aga Khan Foundation Canada as part of the IMPACT project.

\section{Authors contributions}

$\mathrm{CM}, \mathrm{EP}, \mathrm{TM}, \mathrm{KI}, \mathrm{LM}, \mathrm{MM}, \mathrm{MAM}, \mathrm{DS}, \mathrm{MT}$ and GE contributed to the conception and designing of the study.TM conducted the data analysis. TM, MM were involved in the field work. CM, EP drafted the manuscript and CM worked on revising the manuscript to this final draft. CM, EP, TM, KI, LM, SB, MM, JO, DS, MAM, LS, SM, MT and GE critically reviewed and provided inputs to the manuscript. All authors have read and approved the final version of this manuscript.

\section{Acknowledgement}

We thank all HCPs who agreed to participate in this study and the research assistants for their commitment during data collection. We appreciate the support received from the Regional Administrative Secretary, Regional Medical Officer, District Medical Officers, Facility in-charges, and the Health management teams during the baseline survey.

\section{References}


1. Organization WH. Everybody's business-strengthening health systems to improve health outcomes: WHO's framework for action. 2007.

2. Achana F, Debpuur C, Akweongo P, Cleland J. Postpartum abstinence and risk of HIV among young mothers in the Kassena-Nankana district of Northern Ghana. Cult Health Sex: International J Res Intervention Care. 2010;12(5):569 - 81.

3. World Health Organization. Global strategy on human resources of health: workforce 2030. Geneva: WHO; 2016.

4. World Health Organization. Handbook on monitoring and evaluation of human resources for health: with special applications for low- and middle-income countries. 2009.

5. World Health Organization. Working for health and growth: investing in the health workforce. Geneva; 2016.

6. National Bureau of Statistics (NBS). Tanzania demographic and health survey and malaria indicator survey (TDHS-MIS) 2015-16. Dar es Salaam: MoHCDGEC; 2016.

7. The Center for Strategic and International Studies. Maternal, neonatal, and child health in Tanzania. Retrieved from maternaltz.csis.org/tanzania/ on 10th August 2017. 2015.

8. Gourlay A, Wringe A, Birdthistle I, Mshana G, Michael D, Urassa M. "It is like that, we didn't understand each other": exploring the influence of patient-provider interactions on prevention of mother-to-child transmission of HIV service use in rural Tanzania. PloS one. 2014;9(9):e106325-e.

9. Lerberghe W, Matthews Z, Achadi E, Ancona C, Campbell J, Channon A, et al. Midwifery 3: country experience with strengthening of health systems and deployment of midwives in countries with high maternal mortality. The Lancet. 2014;384:1215-25.

10. Hoope-Bender P, de Bernis L, Campbell J, Downe S, Fauveau V, Fogstad H, et al. Midwifery 4: improvement of maternal and newborn health through midwifery. The Lancet. 2014;384:1226-35.

11. Knippenberg K, LawnE, Darmstadt L, Begkoyian G, Fogstad H, Walelign N, et al. Systematic scaling up of neonatal care in countries. The Lancet. 2005;365(9464):1087-98.

12. Ersdal HL, Vossius C, Bayo E, Mduma E, Perlman J, Lippert A, et al. A one-day "Helping Babies Breathe" course improves simulated performance but not clinical management of neonates. Resuscitation. 2013;84(10):1422-7.

13. Kidanto HL, Wangwe P, Kilewo CD, Nystrom L, Lindmark G. Improved quality of management of eclampsia patients through criteria based audit at Muhimbili National Hospital, Dar es Salaam, Tanzania. Bridging the quality gap. BMC Pregnancy Childbirth. 2012;12:134.

14. Mduma E, Ersdal H, Svensen E, Kidanto H, Auestad B, Perlman J. Frequent brief on-site simulation training and reduction in 24-h neonatal mortality--an educational intervention study. Resuscitation. 2015;93:1-7.

15. Mduma E, Ersdal H, Svensen E, Kidanto H, Auestad B, J. P. Frequent brief on-site simulation training and reduction in 24-h neonatal mortality--an educational intervention study. Resuscitation 2013;84:1422-7. 
16. The United Republic of Tanzania. National strategy for growth and reduction of poverty II NSGRP II. Ministry of finance and economic affairs; 2010.

17. National Bureau of Statistics (Tanzania). 2012 Population and housing census: population distribution by administrative areas. Dar es Salaam: Ministry of Finance; 2013.

18. Ministry of Health and Social Welfare. Regional Health System Needs Assessment. 2015.

19. Ministry of Health CD, Gender, Elderly, Children - MoHCDGEC/Tanzania Mainland, Ministry of Health $\mathrm{MoH} /$ Zanzibar, National Bureau of Statistics - NBS/Tanzania, Office of Chief Government Statistician - OCGS/Zanzibar, ICF. Tanzania Demographic and Health Survey and Malaria Indicator Survey 2015-2016. Dar es Salaam, Tanzania: MoHCDGEC, MoH, NBS, OCGS, and ICF; 2016.

20. Hicks C, Hennessy D, F. B. Development of a psychometrically valid training needs analysis instrument for use with primary health care teams. Health Serv Manage Res. 1996;9(4):262-72.

21. Ariff S, Soofi SB, Sadiq K, Feroze AB, Khan S, Jafarey SN, et al. Evaluation of health workforce competence in maternal and neonatal issues in public health sector of Pakistan: an Assessment of their training needs. BMC Health Services Research. 2010;10(1):319.

22. Sodani P, Sharma K. Training Needs Assessment of Public Health Professionals in Maternal and Neonatal Care. Indian Journal of Maternal and Child Health. 2011;13:1-8.

23. Esan OT, Fatusi AO. Performance needs assessment of maternal and newborn health service delivery in urban and rural areas of Osun State, South-West, Nigeria. African journal of reproductive health. 2014;18(2):105-16.

24. Ministry of Health Community Development Gender Elderly and Children (MoHCDGEC) [Tanzania Mainland] MoHMZ, National Bureau of Statistics (NBS), Office of the Chief Government Statistician (OCGS), ICF. Tanzania Demographic and Health Survey and Malaria Indicator Survey (TDHS-MIS) 2015-2016. Dar es Salaam, Tanzania and Rockville, Maryland, USA; 2016.

25. Viljoen M, Coetzee I, Heyns T. Critical Care Nurses' Reasons for Poor Attendance at a Continuous Professional Development Program. Am J Crit Care. 2016;26(1):70-6.

26. Schweitzer DJ, Krassa TJ. Deterrents to nurses' participation in continuing professional development: an integrative literature review. Journal of continuing education in nursing. 2010;41(10):441-7; quiz 89.

27. Ni C, Hua Y, Shao P, Wallen GR, Xu S, Li L. Continuing education among Chinese nurses: a general hospital-based study. Nurse Educ Today. 2014;34(4):592-7.

28. Jowett SM, Macleod J, Wilson S, Hobbs FD. Research in primary care: extent of involvement and perceived determinants among practitioners from one English region. The British journal of general practice : the journal of the Royal College of General Practitioners. 2000;50(454):387-9.

29. Khalaf AJ, Aljowder Al, Buhamaid MJ, Alansari MF, Jassim GA. Attitudes and barriers towards conducting research amongst primary care physicians in Bahrain: a cross-sectional study. BMC family practice. 2019;20(1):20.

30. Hu H, Yu X, Tang Z, Lin L. Research Capacity and Research Training Needs of Clinical Nurses in Suzhou, China. Journal of continuing education in nursing. 2019;50(9):423-32. 
31. Wu X, Wu X, Gao Y, Wang L, Jin J, Li Y, et al. Research-training needs of clinical nurses: A nationwide study among tertiary hospitals in China. Int J Nurs Sci. 2019;6(3):300-8.

32. Gaspard J, Yang C-M. Training needs assessment of health care professionals in a developing country: the example of Saint Lucia. BMC Medical Education. 2016;16(1):112.

33. Kang L, Li Y, Hu S, Chen M, Yang C, Yang BX, et al. The mental health of medical workers in Wuhan, China dealing with the 2019 novel coronavirus. The Lancet Psychiatry. 2020;7(3):e14.

34. Messner DA, Moloney R, Warriner AH, Wright NC, Foster PJ, Saag KG. Understanding practice-based research participation: The differing motivations of engaged vs. non-engaged clinicians in pragmatic clinical trials. Contemporary clinical trials communications. 2016;4:136-40.

35. Siedlecki SL, Albert NM. Research-active clinical nurses: against all odds. J Clin Nurs. 2017;26(56):766-73.

36. Hlahane MS, Greeff M, du Plessis E. Professional nurses' perceptions of the skills required to render comprehensive primary health care services. Curationis. 2006;29(4):82-94.

37. Tarimo EAM, Moyo G, Masenga H, Magesa P, Mzava D. Performance and self-perceived competencies of enrolled nurse/midwives: a mixed methods study from rural Tanzania. BMC Health Services Research. 2018;18(1):277.

38. MOHSW. Human Resource for Health and Social Welfare Strategic plan 2014-2019. Dar es Salaam, Tanzania: Ministry of Health and Social Welfare; 2014.

\section{Figures}




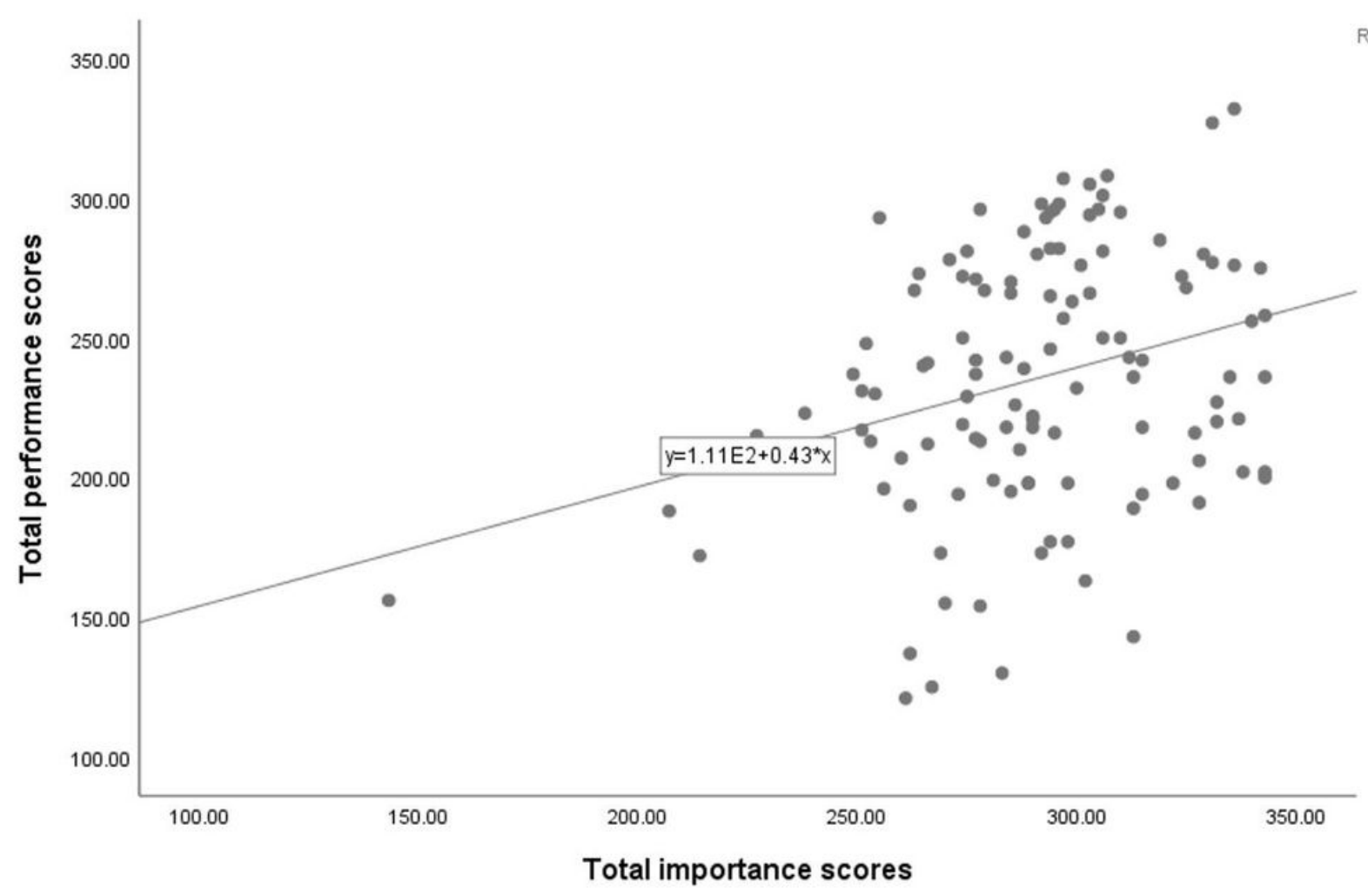

Figure 1

Correlation between perceived importance and performance of task 